\title{
ИССЛЕДОВАНИЕ СВОЙСТВ БИОПОЛИМЕРА, ПОЛУЧЕННОГО В ПРОЦЕССЕ ПЕРЕРАБОТКИ ОРГАНОСОДЕРЖАЩИХ ОТХОДОВ
}

\author{
Григорьев Антон Олегович \\ Майнагашев Кирилл Сергеевич \\ студенты \\ Научный руководитель: Шалбуев Дмитрий Валерьевич \\ д.т.н., проф. \\ ФГБОУ ВО «Восточно-Сибирский государственный \\ университет технологий и управления»
}

\begin{abstract}
Аннотация: в статье представлены результаты изучения физикохимических, коллоидно-химических и реологических свойств биополимера, полученного в процессе рециклизации твердых органосодержащих отходов, образующихся при переработке шкур лап северного оленя.
\end{abstract}

Ключевые слова: биополимер, органосодержащие отходы, рециклизация, коллоидно-химические свойства, лапы северного оленя.

\section{BIOPOLYMER PROPERTIES INVESTIGATION OBTAINED IN THE PROCESS OF ORGAN-CONTAINING WASTE RECYCLING}

\section{Grigoriev Anton Olegovich Mainagashev Kirill Sergeevich Scientific adviser:Shalbuev Dmitry Valeryevich}

\begin{abstract}
The article presents the results of studying the physico-chemical, colloidal-chemical and rheological properties of a biopolymer obtained in the process of solid organ-containing waste recycling generated during the processing of reindeer paw skins.
\end{abstract}

Key words: biopolymer, organ-containing waste, recycling, colloidalchemical properties, reindeer paws.

Кожевенная промышленность образует большое количество твердых органических отходов на разных этапах переработки кожевенного сырья и полуфабриката. Если эти отходы не обрабатывать и не утилизировать, то они, 
в результате возникновения гнилостных процессов, могут вызвать экологическую деградацию почв, а также поверхностных и подземных вод, с поступлением в атмосферу газообразных продуктов гниения.

Проблема переработки отходов приобретает все большее значение в условиях современного и быстро развивающегося общества, основанного на технологических принципах работы. Сейчас в странах развитого общества большое значение начинают уделять процессам, связанным с переработкой отходов различного происхождения. Некоторые страны уже перерабатывают до 70\% отходов, тогда как в России - менее 5\% [1].

Перспективным направлением утилизации органосодержащих отходов является их переработка с целью получения биополимеров, которые за счет определенных физико-химических, коллоидно-химических и структурнореологических свойств, могут быть использованы в различных отраслях народного хозяйства, таких как пищевая, легкая и строительная промышленности, сельское хозяйство, а также в медицинских целях [2].

Исключением не являются предприятия, занимающиеся переработкой лап северного оленя. На этих предприятиях в значительном количестве образуются органосодержащие отходы, которые являются ценным сырьем для получения биоактивного материала - биополимера широкого спектра применения. Согласно Федеральному классификационному каталогу отходов [3] мездра и краевая обрезь, органосодержащий отход, образующихся при переработке лап северного оленя, относятся к 4 классу опасности, что требует проведение дополнительных мероприятий по их утилизации. Особенностью этих отходов является то, что они содержат коллаген, который может быть использован для получения биополимера широкого спектра применения.

Представляет интерес исследовать возможность рециклизацииорганосодержащихотходов и оценка их пригодности для получения биополимера. Целью работы являлось изучение физикохимических, коллоидно-химических и структурно-реологических свойств биополимера, полученного из твердых органосодержащих отходов, образующихся в процессе переработки шкур лап северного оленя.

Для достижения поставленной цели необходимо было решить следующие задачи:

- исследовать физико-химические и коллоидно-химические свойства биополимера, полученного в результате рециклизацииорганосодержащих отходов; 
- изучить аминокислотный состав и структурно-реологические свойства биополимера, полученного из органосодержащих отходов, образующихся в результате переработки лап северного оленя.

Объектом исследования являлись отходы переработки лап северного оленя - краевая обрезь, образующаяся в процессе переработки шкур лап северного оленя, а также биополимер, полученный из нее на кафедре «Технология кожи, меха. Водные ресурсы и товароведение» ВСГУТУ.

Для изучения химического состава краевой обрези лап северного оленя определяли следующие показатели: массовые доли влаги, несвязанных жировых и минеральных веществ, $\mathrm{pH}$ водной вытяжки, а также содержание белка по Кьельдалю. Изучение химических свойств биополимера, полученного из краевой обрези лап северного оленя, проводили стандартными методами, применяемыми при оценке качества овчинно-шубного сырья. Для оценки коллоидно-химических свойств полученного биополимера использовали сталагмометрический метод. Определение реологических свойств биополимера проводили на ротационном вискозиметре Brookfield DV3T. Аминокислотный состав биополимера, полученного из краевой обрези лап северного оленя, определяли на приборе «Капель 105 М» (система капиллярного электрофореза).

Результаты физико-химического анализа состава краевой обрези лап северного оленя представлены в таблице 1 .

Таблица 1

Сводные данные оценки физико-химических свойств краевой обрези лап северного оленя

\begin{tabular}{|l|c|}
\hline \multicolumn{1}{|c|}{ Показатель } & Значение \\
\hline Массовая доля влаги, \% & 26,7 \\
\hline Массовая доля несвязанных жировых веществ, \% & 1,8 \\
\hline Массовая доля минеральных веществ, \% & 0,4 \\
\hline Массовая доля азота, \% & 1,4 \\
\hline Массовая доля белка, \% & 8,9 \\
\hline рН водной вытяжки & 4,8 \\
\hline
\end{tabular}

Как видно из данных таблицы 1, массовая доля белка в краевой обрези лап северного оленя составила $8,9 \%$, что позволяет рекомендовать данный органосодержащий отход в качестве сырья для получения биополимера. 
Кроме того, данный материал содержит низкое количество жировых и минеральных веществ - 1,8 и $0,4 \%$, соответственно.

Органолептические свойства полученного биополимера представлены в таблице 2.

Таблица 2

Органолептические свойства биополимера

\begin{tabular}{|l|l|}
\hline \multicolumn{1}{|c|}{ Показатель } & \multicolumn{1}{c|}{ Биополимер - кислотный метод (БПк) } \\
\hline Запах & Свойственный сырью животного происхождения \\
\hline Цвет & Светло бежевый \\
\hline Наличие осадка & Отсутствует \\
\hline Консистенция & Желеобразная \\
\hline
\end{tabular}

Из таблицы 2 видно, что по органолептическим показателям биополимер характеризовался запахом животного происхождения, бежевым цветом и отсутствием осадка.

Определение физико-химических свойств полученного белкового гидролизата проводили по следующим показателям: определение массовой доли жировых веществ, минеральных веществ, сухого остатка, белка и азота. Результаты исследования представлены в таблице 3.

Таблица 3

Сводные данные оценки физико-химических свойств биополимера, полученного кислотным методам

\begin{tabular}{|c|c|}
\hline Показатель & $\begin{array}{c}\text { Параметры биополимера, } \\
\text { полученного кислотным методом }\end{array}$ \\
\hline Массовая доля азота, \% & $3,5 \pm 0,2$ \\
\hline Массовая доля белка, \% & $21,8 \pm 1,1$ \\
\hline Массовая доля несвязанных жировых веществ, \% & $5,6 \pm 0,1$ \\
\hline Массовая доля минеральных веществ, \% & $0,02 \pm 0,01$ \\
\hline Массовая доля сухого остатка, \% & $5,5 \pm 0,6$ \\
\hline 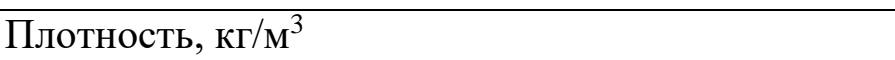 & 1320 \\
\hline $\mathrm{pH}$ & $4,8 \pm 0,1$ \\
\hline
\end{tabular}

Анализируя данные представленные в таблице 3 можно отметить, что полученный биополимер характеризовался кислым значением $\mathrm{pH}$ (менее 5), высоким содержанием белка (более 20\%), а также присутствием жировых и минеральных веществ. 
Таким образом, на основании проведенных исследований были изучены физико-химические свойства органосодержащих отходов, полученных после переработки лап северного оленя, и показана принципиальная возможность их применения для получения биополимера.

На основе использования метода кислотного гидролиза получен биополимер и изучены его физико-химические свойства.

Для определения коллоидно-химических свойств биополимера, полученного из краевой обрези лап северного оленя, готовили водные растворы, содержащие полученный биополимер, следующих концентраций, С, г/дм²: $0 ; 0,4 ; 0,7 ; 1,4 ; 3,0 ; 6,0 ; 9,0$ и 12,0. Водные растворы готовили следующим образом: соответствующее количество биополимера смешивали с дистиллированной водой и встряхивали в течение 1 мин. В качестве раствора сравнения использовали дистиллированную воду.

Измерение коэффициента поверхностного натяжения проводили сталагмометрическим методом. Результаты исследования представлены на рисунке 1 .

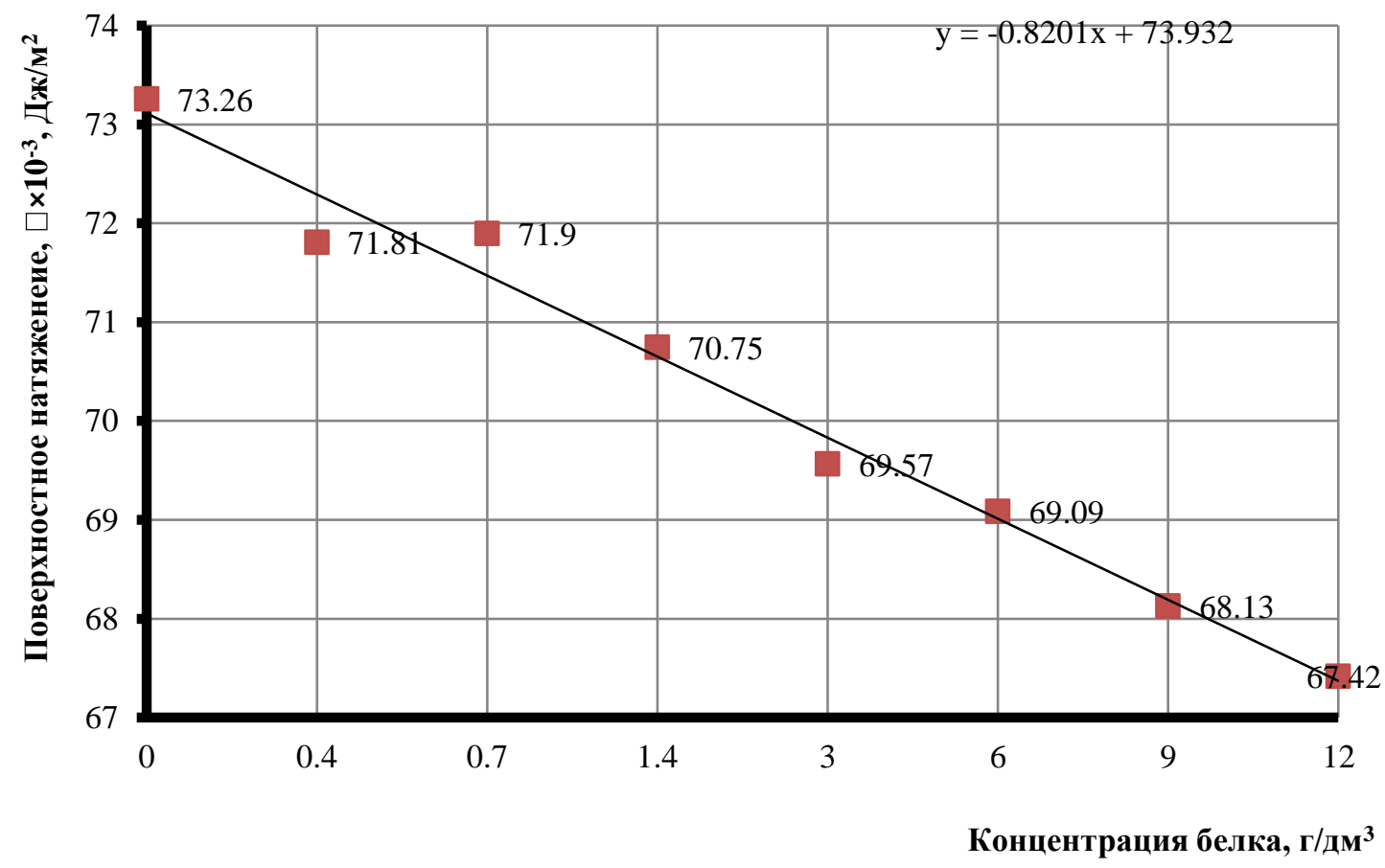

\section{Рис. 1. Влияние расхода биополимера на изменение поверхностного натяжения системы биополимер-вода}

Как видно из рисунка 1 повышение концентрации биополимера в водном растворе с 0 до 12 г/дм ${ }^{3}$ приводит к уменьшению поверхностного натяжения с $73,26 \times 10^{-3}$ до $67,42 \times 10^{-3}$ Дж/ $\mathrm{M}^{2}$. Увеличение концентрации 199 
биополимера в водном растворе характеризовалось резким снижением величины поверхностного натяжения в области малых концентраций, до 3 г/дм ${ }^{3}$, выше которых значения поверхностного натяжения изменялось незначительно.

Анализируя полученные данные можно констатировать, что биополимер, полученный из краевой обрези лап северного оленя, обладал оптимальными коллоидно-химическими свойствами, что позволило отнести его к биологическим поверхностно-активным веществам (биоПАВ).

Известно [4], что изменения структурно-механических свойств систем обусловлены взаимодействиями частиц со средой и между собой, исследовать которые позволяют методы реологии. В связи с этим, представляло интерес изучение структуры биополимера, полученного из краевой обрези лап северного оленя и, возможности, его отнесения к определенному типу реологической жидкости.Результаты измерения представлены на рисунке 2.

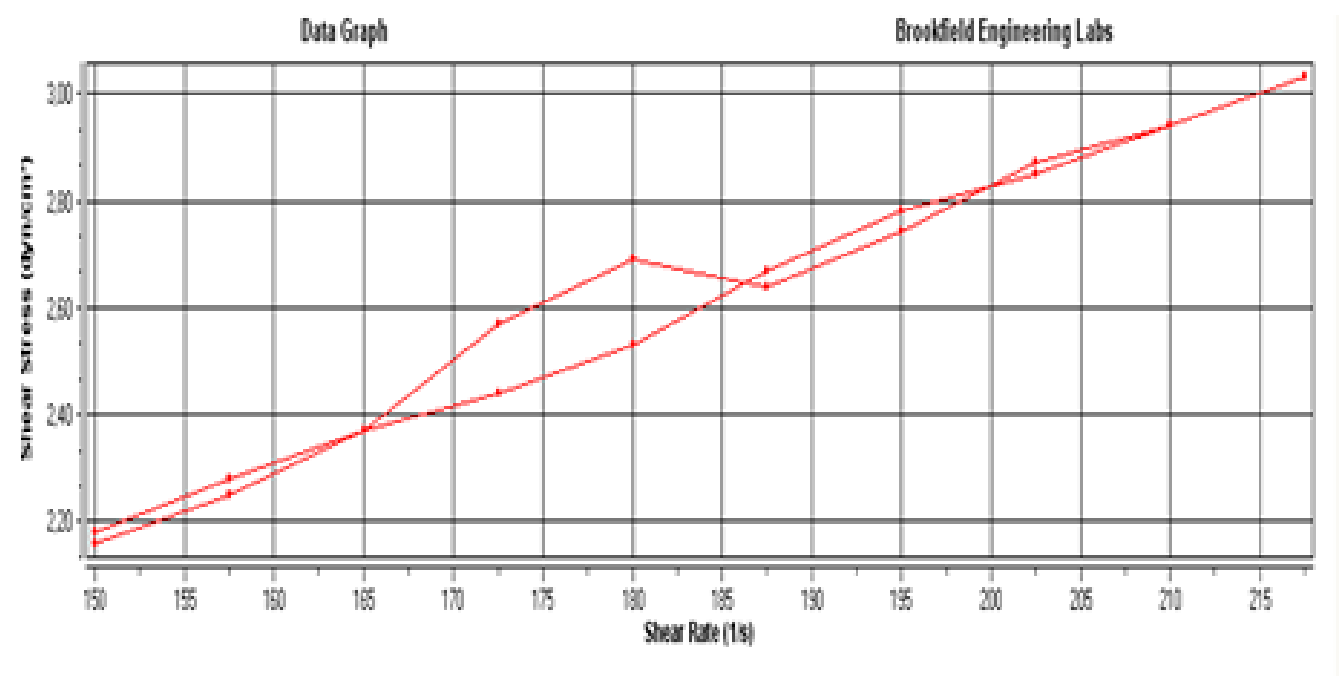

Рис. 2. Изменение динамической вязкости биополимера от скорости вращения шпинделя

На рисунке 2 видно, что образцы способны восстанавливать структуру при приложении механического воздействия шпинделя. Таким образом, исследуемый биополимер отнесли к тиксотропным подсистемам, так как кажущаяся вязкость незначительно понижалась с продолжительностью сдвига.

Для выбора математической модели реологического поведения объекта программа вискозиметра Reocalc автоматически пересчитывала зависимость «скорость сдвига - напряжение сдвига» и предлагала на выбор модели с 
различным коэффициентом сходимости (CoF). Было установлено, что исследуемый биополимер, скорее всего, является неньютоновской жидкостью (т.е. не изменяет своих свойств во времени и при приложении нагрузки) и его поведение можно описать степенным законом (PowerLaw).

Аминокислоты являются важным компонентом биополимера в случае его использования в сельском хозяйстве в качестве удобрения или кормовой добавки.

Интерес представляло изучение аминокислотного состава биополимера, полученного из краевой обрези лап северного оленя. Результаты исследования представлены на рисунке 3 .

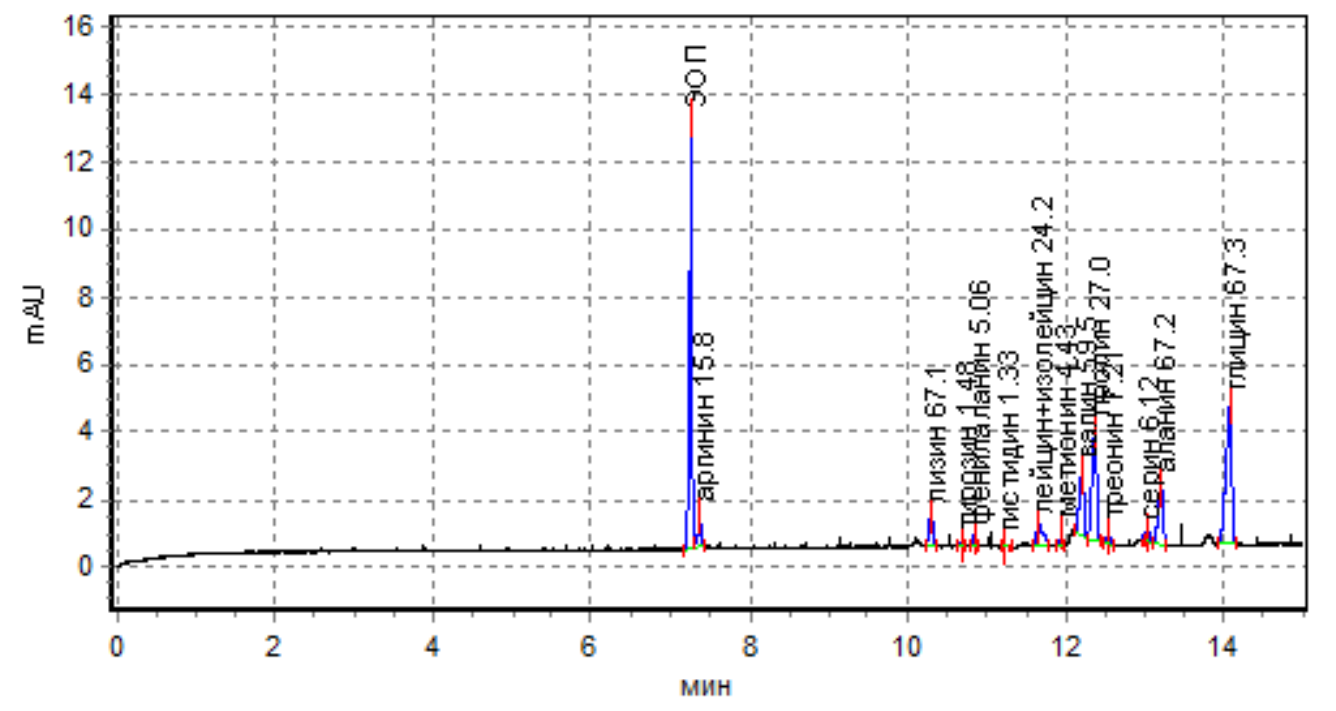

\section{Рис. 3. Аминокислотный состав биоплимера, полученного из краевой обрези лап северного оленя}

В процессе исследования было выявлено (рисунок 3), что биополимер, полученный из краевой обрези лап северного оленя, содержал различные виды аминокислот. Максимальная концентрация приходилась на такие аминокислоты, как, мг/дм²: аланин $(67,2)$, глицин $(67,3)$ и лизин $(67,1)$. Несколько меньше присутствовали пролин $\left(27,0\right.$ мг/дм $\left.{ }^{3}\right)$ и лейцин+изолейцин $(24,2$ мг/дм³ $)$. Концентрации триптофана составила 0,4 мг/дм².

Таким образом, в результате проведенного исследования была показана возможность получения биоактивного материала из краевой обрези лап северного оленя. Данный биополимер обладал оптимальными коллоиднохимическим свойствами, что подтверждалось снижением величины поверхностного натяжения водных растворов биополимера, что позволило отнести данный продукт к биоПАВ. Присутствие значительного количества 
аминокислот, позволяет рекомендовать полученный биополимер к использованию в различных отраслях, в частности, в сельском хозяйстве, легкой и пищевой промышленностях и т.д.

\section{Список литературы}

1 Проблема отходов URL: http://www.greenpeace.org/russia/ru/ campaigns/waste (Дата обращения 17.02.21).

2 Отходы кожевенного производства и их переработка URL: http://www.collagen.su/archives/2574 (Дата обращения 23.02.21).

3 Приказ Росприроднадзора от 22 мая 2017 года №242 (ред. от 02.11.2018) «Об утверждении Федерального классификационного каталога отходов (Зарегистрировано в Минюсте России от 08.06.2017 №47008) URL: http://www.consultant.ru/document/cons_doc_LAW_218071/2ff7a8c72de3994f304 96a0ccbb1ddafdaddf5 18/ (Дата обращения 01.03.2021).

4 Рейнер М. Реология. Пер. с англ. М.: Наука, 1965, 224 с. 